\title{
NUMERICAL OPTIMIZATION OF A THREE-CHAMBER MUFFLER HYBRIDIZED WITH A SIDE INLET AND A PERFORATED TUBE BY SA METHODM
}

Min-Chie Chiu

Department of Automatic Control Engineering, ChungChou Institute of Technology, 6, Lane 2, Sec. 3, Shanchiao Rd., Yuanlin, Changhua 51003, Taiwan, R.O.C., minchie.chiu@msa.hinet.net

Follow this and additional works at: https://jmstt.ntou.edu.tw/journal

Part of the Electrical and Computer Engineering Commons

\section{Recommended Citation}

Chiu, Min-Chie (2010) "NUMERICAL OPTIMIZATION OF A THREE-CHAMBER MUFFLER HYBRIDIZED WITH A SIDE INLET AND A PERFORATED TUBE BY SA METHODM," Journal of Marine Science and Technology. Vol. 18: Iss. 4, Article 2.

DOI: $10.51400 / 2709-6998.1897$

Available at: https://jmstt.ntou.edu.tw/journal/vol18/iss4/2

This Research Article is brought to you for free and open access by Journal of Marine Science and Technology. It has been accepted for inclusion in Journal of Marine Science and Technology by an authorized editor of Journal of Marine Science and Technology. 
NUMERICAL OPTIMIZATION OF A THREE-CHAMBER MUFFLER HYBRIDIZED

WITH A SIDE INLET AND A PERFORATED TUBE BY SA METHODM

Acknowledgements

The author acknowledges the financial support of the National Science Council (NSC 95-2218-E-235-002), ROC. 


\title{
NUMERICAL OPTIMIZATION OF A THREE-CHAMBER MUFFLER HYBRIDIZED WITH A SIDE INLET AND A PERFORATED TUBE BY SA METHOD
}

\author{
Min-Chie Chiu*
}

Key words: multi-chamber, internal perforated tube, four-pole transfer matrix method, space constraints, SA optimization.

\begin{abstract}
Research on new techniques of multi-chamber mufflers equipped with a side inlet and an internal non-perforated tube has been well addressed and developed; however, the research work of multi-chamber mufflers in conjunction with side inlet and internal perforated tubes which may efficiently increase the acoustical performance is rare. Therefore, the main purpose of this paper is to not only analyze the sound transmission loss (STL) of three-chamber side mufflers with a perforated tube but also to optimize their best design shape under a limited space. In this paper, both the generalized decoupling technique and plane wave theory in solving the coupled acoustical problem are used. The four-pole system matrix in evaluating the acoustic performance is also deduced in conjunction with a simulated algorithm (SA). To verify the liability of the SA technique, the noise minimization of muffles at a targeted frequency is exemplified first. To appreciate the acoustical performance of various multi-chamber mufflers with/without inner perforated tube, three kinds of multi-chamber mufflers - a one-chamber side muffler, a two-chamber side muffler hybridized with a non-perforated tube, and a three-chamber side muffler hybridized with a perforated tube are introduced and assessed. In eliminating the broadband exhausted noise emitted from an air compressor's inlet. Before the SA operation can be carried out, the accuracies of the mathematical models have to be checked by experimental data.
\end{abstract}

The result reveals a three-chamber side muffler hybridized with a perforated tube exhibits an excellent acoustical ability beyond the other mufflers. Consequently, the approach used

Paper submitted 10/10/08; accepted 07/08/09. Author for correspondence: Min-Chie Chiu (e-mail: minchie.chiu@msa.hinet.net).

*Department of Automatic Control Engineering, ChungChou Institute of Technology, 6, Lane 2, Sec. 3, Shanchiao Rd., Yuanlin, Changhua 51003, Taiwan, R.O.C seeking the optimal design of the $S T L$ proposed in this study is indeed easy, economical and quite effective.

\section{INTRODUCTION}

High noise levels will induce psychological and physiological ailments [1] to people; therefore, the demand of low-noise levels of various products have becomes vital and compulsory [8]. In dealing with horizontal industrial noise which is emitted from a perpendicular vertical system, a side-inlet muffler is customarily used [10] and widely discussed [13].

As the constrained problem is mostly concerned with the necessity of operation and maintenance in practical engineering work, there, therefore, is a growing need to optimize the acoustical performance under limited space. In previous work, the shape optimization of a side inlet/out simpleexpansion muffler has been discussed [23, 4]. Moreover, a mechanism of two-chamber muffler equipped with an internal non-perforated tube has been addressed [5, 3]. However, the acoustical performance is still insufficient within spaceconstrained criteria. The assessment of a new acoustical element - internal perforated tube - was started and discussed by Sullivan and Crocker in 1978 [21]. Based on the coupled equations derived by Sullivan and Crocker, a series of theory and numerical techniques in decoupling the acoustical problems have been proposed [17-19, 20, 22]; Considering the flowing effect, Munjal [12] and Peat [15] broadcast the generalized decoupling and numerical decoupling methods. However, the application of a perforated tube in the side muffler is rarely tackled. To increase the acoustical performance, a three-chamber side muffler hybridized with an inner perforated tube which may dramatically depress the sound energies is proposed.

The simulated annealing (SA) method, a stochastic relaxation technique oriented by Metropolis et al. [11] and developed by Kirkpatrick et al. [9] imitating the physical process of annealing metal to reach the minimum energy state, is applied in this work. In this paper, to facilitate the evaluation of the muffler performance in acoustic, a four-pole system matrix in 
evaluating the acoustic performance (STL) is also deduced. By adjusting the muffler's shape and using the SA method and numerical decoupling methods, the optimal acoustical performances of mufflers can be achieved.

\section{MATHEMATICAL MODELS}

In this paper, a side-inlet muffler was adopted for the noise elimination on the constrained air compressor room shown in Fig. 1. As indicated in Fig. 2, this three-chamber side muffler system hybridized with a perforated tube consists of eleven acoustical elements. Five kinds of muffler components, including a straight duct, a side duct, an extended duct, a perforated tube, and a contracted duct are recognized, symbolized as I, II, III, IV and III, and shown in Fig. 3. In Fig. 4, the acoustic pressure $p$ and acoustic particle velocity $u$ with respect to three kinds of mufflers are represented by seven nodes, thirteen nodes and fifteen nodes correspondingly.

\section{System Matrix}

Individual transfer matrixes with respect to each case of straight ducts (I), side tube (II), extended tube (III), perforated resonator (IV) and contracted tube (V) are described as follows:

As deduced in previous studies [4, 5, 23], the four-pole matrix for a straight tube (I) between nodes 1 and 2 is

$\left(\begin{array}{c}p_{1} \\ \rho_{o} c_{o} u_{1}\end{array}\right)=e^{-j M M_{1} k L_{1} /\left(1-M_{1}^{2}\right)}\left[\begin{array}{cc}T S 31_{1,1} & T S 31_{1,2} \\ T S 31_{2,1} & T S 31_{2,2}\end{array}\right]\left(\begin{array}{c}p_{2} \\ \rho_{o} c_{o} u_{2}\end{array}\right)$

$T S 31_{1,1}=\cos \left[\frac{k L_{1}}{1-M_{1}^{2}}\right] ; T S 31_{1,2}=j \sin \left[\frac{k L_{1}}{1-M_{1}^{2}}\right]$

$T S 31_{2,1}=j \sin \left[\frac{k L_{1}}{1-M_{1}^{2}}\right] ; T S 31_{2,2}=\cos \left[\frac{k L_{1}}{1-M_{1}^{2}}\right]$

As derived in previous studies [4, 5, 13, 23], the four-pole matrix for a side tube (II) between nodes 2 and 4 is

$$
\left(\begin{array}{c}
p_{2} \\
\rho_{o} c_{o} u_{2}
\end{array}\right)=\left[\begin{array}{cc}
T E 31_{1,1} & T E 31_{1,2} \\
T E 31_{2,1} & T E 31_{2,2}
\end{array}\right]\left(\begin{array}{c}
p_{4} \\
\rho_{o} c_{o} u_{4}
\end{array}\right)
$$

$$
\begin{aligned}
& T E 31_{1,1}=1-j \frac{M_{2} S_{3}}{S_{2}} \tan \left(k L_{2}\right) \\
& T E 31_{1,2}=\left[M_{4}\left[1+\left(\frac{S_{4}}{S_{2}}-1\right)^{2}\right]-M_{2} \frac{S_{4}}{S_{2}}\right]+j \frac{0.85 k D_{1} S_{4}}{2 S_{2}} ; \\
& T E 31_{2,1}=j \frac{S_{3}}{S_{2}} \tan \left(k L_{2}\right) ; T E 31_{1,1}=\frac{S_{4}}{S_{2}}
\end{aligned}
$$

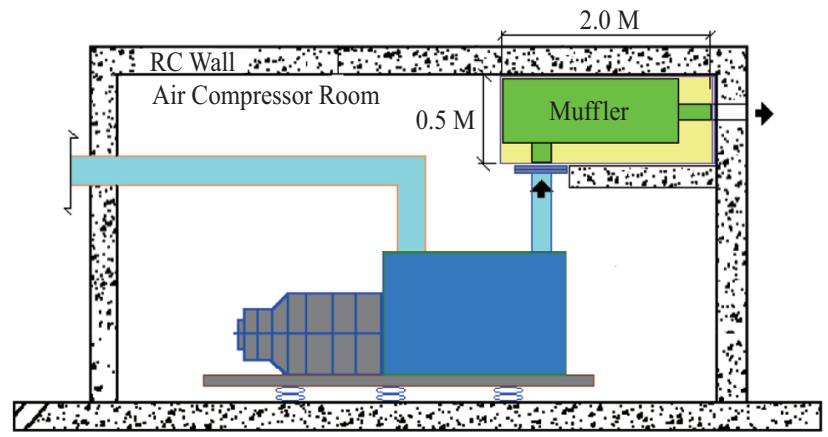

Fig. 1. Elevation drawing of an air compressor.

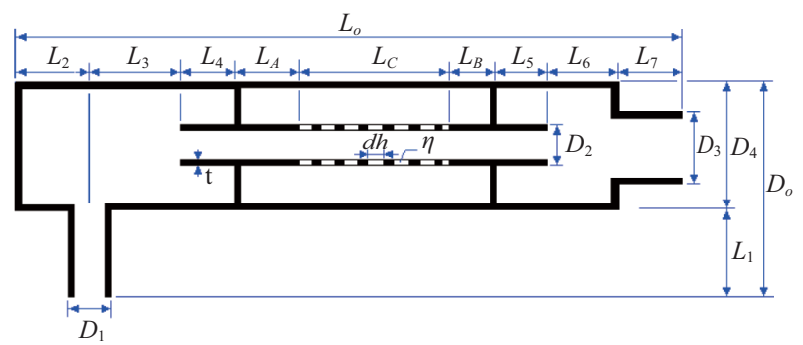

Fig. 2. The outline of a three-chamber side muffler hybridized with a perforated tube.

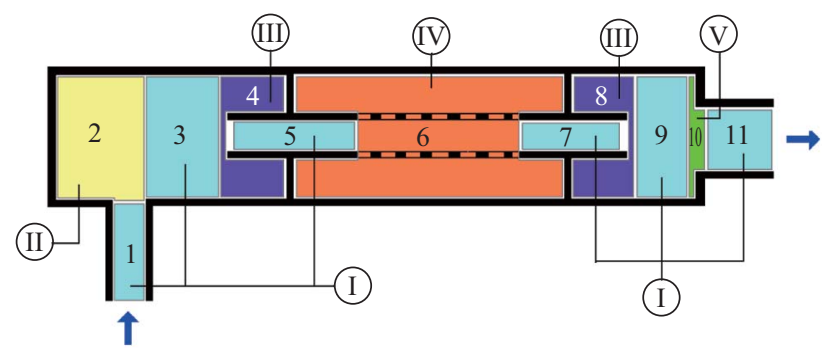

Fig. 3. Acoustical elements of a three-chamber side muffler hybridized with a perforated tube.

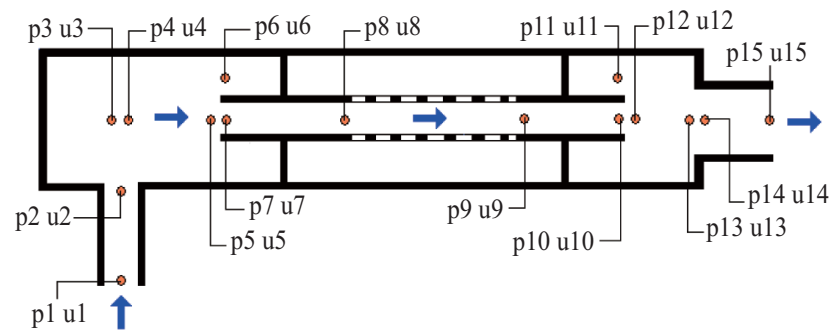

Fig. 4. Acoustical field of a three-chamber side muffler hybridized with a perforated tube.

Similarly, the four-pole matrix for a straight tube (I) between nodes 4 and 5 is [4, 5, 23]

$\left(\begin{array}{c}p_{4} \\ \rho_{o} c_{o} u_{4}\end{array}\right)=e^{-j M_{4} k L_{3} /\left(1-M_{4}^{2}\right)}\left[\begin{array}{ll}T S 32_{1,1} & T S 32_{1,2} \\ T S 32_{2,1} & T S 32_{2,2}\end{array}\right]\left(\begin{array}{c}p_{5} \\ \rho_{o} c_{o} u_{5}\end{array}\right)$ 
$T S 32_{1,1}=\cos \left[\frac{k L_{3}}{1-M_{4}^{2}}\right] ; T S 32_{1,2}=j \sin \left[\frac{k L_{3}}{1-M_{4}^{2}}\right] ;$

$T S 32_{2,1}=j \sin \left[\frac{k L_{3}}{1-M_{4}^{2}}\right] ; T S 32_{2,2}=\cos \left[\frac{k L_{3}}{1-M_{4}^{2}}\right]$

As derived in previous studies [3, 5], the matrix for a non-perforated extended tube (III) between nodes 5 and 7 is

$$
\left(\begin{array}{c}
p_{5} \\
\rho_{o} c_{o} u_{5}
\end{array}\right)=\left[\begin{array}{ll}
T S E C 31_{1,1} & T S E C 31_{1,2} \\
T S E C 31_{2,1} & T S E C 31_{2,2}
\end{array}\right]\left(\begin{array}{c}
p_{7} \\
\rho_{o} c_{o} u_{7}
\end{array}\right)
$$

Likewise, the four-pole matrix for a straight tube (I) between nodes 7 and 8 is $[4,5,23]$

$\left(\begin{array}{c}p_{7} \\ \rho_{o} c_{o} u_{7}\end{array}\right)=e^{-j M_{7} k\left(L_{4}+L_{A}\right) /\left(1-M_{7}^{2}\right)}\left[\begin{array}{cc}T S 33_{1,1} & T S 33_{1,2} \\ T S 33_{2,1} & T S 33_{2,2}\end{array}\right]\left(\begin{array}{c}p_{8} \\ \rho_{o} c_{o} u_{8}\end{array}\right)$

$$
\begin{aligned}
& T S 33_{1,1}=\cos \left[\frac{k\left(L_{4}+L_{A}\right)}{1-M_{7}^{2}}\right] ; T S 33_{1,2}=j \sin \left[\frac{k\left(L_{4}+L_{A}\right)}{1-M_{7}^{2}}\right] \\
& T S 33_{2,1}=j \sin \left[\frac{k\left(L_{4}+L_{A}\right)}{1-M_{7}^{2}}\right] ; T S 33_{2,2}=\cos \left[\frac{k\left(L_{4}+L A\right)}{1-M_{7}^{2}}\right](5 \mathrm{~b})
\end{aligned}
$$

As derived in Appendix A [6, 12, 15], the matrix for a perforated resonator (IV) between nodes 8 and 9 is

$$
\left(\begin{array}{c}
p_{8} \\
\rho_{o} c_{o} u_{8}
\end{array}\right)=\left[\begin{array}{cc}
T P 31_{1,1} & T P 31_{1,2} \\
T P 31_{2,1} & T P 31_{2,2}
\end{array}\right]\left(\begin{array}{c}
p_{9} \\
\rho_{o} c_{o} u_{9}
\end{array}\right)
$$

In the same way, the four-pole matrix for a straight tube (I) between nodes 9 and 10 is [4, 5, 23]

$$
\left(\begin{array}{c}
p_{9} \\
\rho_{o} c_{o} u_{9}
\end{array}\right)=e^{-j M_{9} k\left(L_{5}+L_{B}\right) /\left(1-M_{9}^{2}\right)}\left[\begin{array}{ll}
T S 34_{1,1} & T S 34_{1,2} \\
T S 34_{2,1} & T S 34_{2,2}
\end{array}\right]\left(\begin{array}{c}
p_{10} \\
\rho_{o} c_{o} u_{10}
\end{array}\right)
$$

$$
\begin{aligned}
& T S 34_{1,1}=\cos \left[\frac{k\left(L_{5}+L_{B}\right)}{1-M_{9}^{2}}\right] ; T S 34_{1,2}=j \sin \left[\frac{k\left(L_{5}+L_{B}\right)}{1-M_{9}^{2}}\right] \\
& T S 34_{2,1}=j \sin \left[\frac{k\left(L_{5}+L_{B}\right)}{1-M_{9}^{2}}\right] ; T S 34_{2,2}=\cos \left[\frac{k\left(L_{5}+L_{B}\right)}{1-M_{9}^{2}}\right]
\end{aligned}
$$

Likewise, the matrix for a non-perforated extended tube (III) between nodes 10 and 12 is $[3,5]$

$$
\left(\begin{array}{c}
p_{10} \\
\rho_{o} c_{o} u_{10}
\end{array}\right)=\left[\begin{array}{cc}
T S E E 31_{1,1} & T S E E 31_{1,2} \\
T S E E 31_{2,1} & T S E E 31_{2,2}
\end{array}\right]\left(\begin{array}{c}
p_{12} \\
\rho_{o} c_{o} u_{12}
\end{array}\right)
$$

The four-pole matrix for a straight tube (I) between nodes 12 and 13 is $[4,5,23]$

$\left(\begin{array}{c}p_{12} \\ \rho_{o} c_{o} u_{12}\end{array}\right)=e^{-j M_{12} k L_{6}\left(1-M_{12}^{2}\right)}\left[\begin{array}{ll}T S 35_{1,1} & T S 35_{1,2} \\ T S 35_{2,1} & T S 35_{2,2}\end{array}\right]\left(\begin{array}{c}p_{13} \\ \rho_{o} c_{o} u_{13}\end{array}\right)$

$$
\begin{aligned}
& T S 35_{1,1}=\cos \left[\frac{k L_{6}}{1-M_{12}^{2}}\right] ; T S 35_{1,2}=j \sin \left[\frac{k L_{6}}{1-M_{12}^{2}}\right] ; \\
& T S 35_{2,1}=j \sin \left[\frac{k L_{6}}{1-M_{12}^{2}}\right] ; T S 35_{2,2}=\cos \left[\frac{k L_{6}}{1-M_{12}^{2}}\right]
\end{aligned}
$$

The four-pole matrix for a contracted tube $(\mathrm{V})$ between nodes 12 and 13 is [12]

$$
\begin{gathered}
\left(\begin{array}{c}
p_{13} \\
\rho_{o} c_{o} u_{13}
\end{array}\right)=\left[\begin{array}{ll}
T C 31_{1,1} & T C 31_{1,2} \\
T C 31_{2,1} & T C 31_{2,2}
\end{array}\right]\left(\begin{array}{c}
p_{14} \\
\rho_{o} c_{o} u_{14}
\end{array}\right) \\
T C 31_{1,1}=1 ; T C 31_{1,2}=0 ; T C 31_{2,1}=0 ; T C 31_{2,2}=\frac{S_{14}}{S_{13}}
\end{gathered}
$$

The four-pole matrix for a straight tube (I) between nodes 14 and 15 is $[4,5,23]$

$$
\left(\begin{array}{c}
p_{14} \\
\rho_{o} c_{o} u_{14}
\end{array}\right)=e^{-j M_{14} k L_{7} /\left(1-M_{14}^{2}\right)}\left[\begin{array}{cc}
T S 36_{1,1} & T S 36_{1,2} \\
T S 36_{2,1} & T S 36_{2,2}
\end{array}\right]\left(\begin{array}{c}
p_{15} \\
\rho_{o} c_{o} u_{15}
\end{array}\right)
$$

$$
\begin{aligned}
& T S 36_{1,1}=\cos \left[\frac{k L_{7}}{1-M_{14}^{2}}\right] ; T S 36_{1,2}=j \sin \left[\frac{k L_{7}}{1-M_{14}^{2}}\right] ; \\
& T S 36_{2,1}=j \sin \left[\frac{k L_{7}}{1-M_{14}^{2}}\right] ; T S 36_{2,2}=\cos \left[\frac{k L_{7}}{1-M_{14}^{2}}\right]
\end{aligned}
$$

The total transfer matrix assembled by multiplication is 


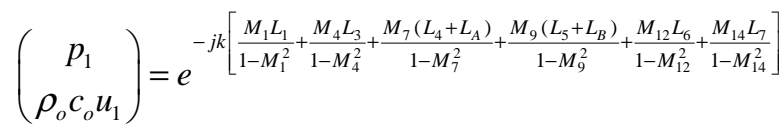

$\left[\begin{array}{ll}T S 31_{1,1} & T S 31_{1,2} \\ T S 31_{2,1} & T S 31_{2,2}\end{array}\right]\left[\begin{array}{ll}T E 31_{1,1} & T E 31_{1,2} \\ T E 31_{2,1} & T E 31_{2,2}\end{array}\right]\left[\begin{array}{ll}T S 32_{1,1} & T S 32_{1,2} \\ T S 32_{2,1} & T S 32_{2,2}\end{array}\right]$

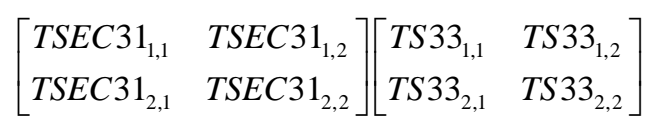

$\left[\begin{array}{cc}T P 31_{1,1} & T P 31_{1,2} \\ T P_{2,1} & T P 31_{2,2}\end{array}\right]\left[\begin{array}{ll}T S 34_{1,1} & T S 34_{1,2} \\ T S 34_{2,1} & T S 34_{2,2}\end{array}\right]$

$\left[\begin{array}{ll}\text { TSEE31 } & \text { TSEE31 }_{1,2} \\ \text { TSEE31 } & \text { TSEE31 }_{2,2}\end{array}\right]\left[\begin{array}{ll}T S 35_{1,1} & T S 35_{1,2} \\ T S 35_{2,1} & T S 35_{2,2}\end{array}\right]$

$\left[\begin{array}{ll}T C 31_{1,1} & T C 31_{1,2} \\ T C 31_{2,1} & T C 31_{2,2}\end{array}\right]\left[\begin{array}{ll}T S 36_{1,1} & T S 36_{1,2} \\ T S 36_{2,1} & T S 36_{2,2}\end{array}\right]\left(\begin{array}{c}p_{15} \\ \rho_{o} c_{o} u_{15}\end{array}\right)$

A simplified form in matrix is expressed as

$$
\left(\begin{array}{c}
p_{1} \\
\rho_{o} c_{o} u_{1}
\end{array}\right)=\left[\begin{array}{cc}
T_{11}^{*} & T_{12}^{*} \\
T_{21}^{*} & T_{22}^{*}
\end{array}\right]\left(\begin{array}{c}
p_{15} \\
\rho_{o} c_{o} u_{15}
\end{array}\right)
$$

According to Appendix D, the sound transmission loss (STL) of a muffler is defined as [12]

$\operatorname{STL}\left(Q, f, L_{\mathrm{Z1}}, L_{\mathrm{Z} 2}, L_{\mathrm{Z3}}, A f_{33}, A f c, A f_{35}, D_{4}, A d_{32}, A d_{33}, \eta, d h\right)$

$$
=20 \log \left(\frac{\left|T_{11}^{*}+T_{12}^{*}+T_{21}^{*}+T_{22}^{*}\right|}{2}\right)+10 \log \left(\frac{S_{1}}{S_{14}}\right)
$$

where

$$
\begin{aligned}
& L_{o}=L_{Z 1}+L_{Z 2}+L_{Z 3}+L_{7} ; D_{o}=L_{1}+D_{4} ; \\
& L_{Z 1}=L_{2}+L_{3}+L_{4} ; L_{Z 2}=L_{A}+L_{C}+L_{B} ; L_{Z 3}=L_{5}+L_{6} ; \\
& A f_{33}=L_{3} / L_{Z 1} ; A f C=L_{C} / L_{Z 2} ; A f_{35}=L_{5} / L_{Z 3} ; \\
& A d_{22}=D_{2} / D_{4} ; A d_{23}=D_{3} / D_{4} ; L_{2}=\left(L_{Z 1}-L_{3}\right) / 2 ; \\
& L_{A}=\left(L_{Z 2}-L_{C}\right) / 2 ; L_{4}=L_{2} ; L_{B}=L_{A}
\end{aligned}
$$

\section{Overall Sound Power Level}

The silenced octave sound power level emitted from a silencer's outlet is

$$
S W L_{i}=S W L O_{i}-S T L_{i}
$$

Where (1) $S W L O_{i}$ is the original SWL at inlet of a muffler (or pipe outlet), and $i$ is the index of the octave band frequency.

(2) $S T L_{i}$ is the muffler's STL with respect to the relative octave band frequency.

(3) $S W L_{i}$ is the silenced SWL at the outlet of a muffler with respect to the relative octave band frequency Finally, the overall $S W L_{T}$ silenced by a muffler at the outlet is

$$
\begin{aligned}
& S W L_{T}=10^{*} \log \left\{\sum_{i=1}^{8} 10^{S W L_{i} / 10}\right\} \\
& =10 * \log \left\{\begin{array}{ccc}
{[S W L O(f=63)-} & {[S W L O(f=125)-} & {[S W L O(f=250)-} \\
10^{S T L(f=63)] / 10}+10^{S T L(f=125)]}+10^{S T L(f=250)] / 10} \\
{[S W L O(f=500)-} & S W L O(f=1000)- & S W L O(f=2000)- \\
+10^{S T L(f=500)] / 10} & +10^{S T L(f=1000)] / 10}+10^{S T L(f=2000)] / 10} \\
{[S W L O(f=4000)-} & \\
+10^{S T L(f=4000)] / 10} &
\end{array}\right\}
\end{aligned}
$$

\section{Objective Function}

By using the formula of Eqs. (13) (15), the objective function used in SA optimization was established as

$O B J_{1}=S T L\left(Q, f, L_{\mathrm{Z} 1}, L_{\mathrm{Z} 2}, L_{\mathrm{Z} 3}, A f_{33}, A f c, A f_{35}, D_{4}, A d_{32}, A d_{33}, \eta, d h\right)$

$$
=20 \log \left(\frac{\left|T_{11}^{*}+T_{12}^{*}+T_{21}^{*}+T_{22}^{*}\right|}{2}\right)+10 \log \left(\frac{S_{1}}{S_{14}}\right)
$$

$O B J_{2}=S W L_{T}\left(Q, L_{\mathrm{Z} 1}, L_{\mathrm{Z} 2}, L_{\mathrm{Z} 3}, A f_{33}, A f c, A f_{35}, D_{4}, A d_{32}, A d_{33}, \eta, d h\right)$

$$
=20 \log \left(\frac{\left|T_{11}^{*}+T_{12}^{*}+T_{21}^{*}+T_{22}^{*}\right|}{2}\right)+10 \log \left(\frac{S_{1}}{S_{14}}\right)
$$

where

$$
\begin{aligned}
& L_{o}=L_{Z 1}+L_{Z 2}+L_{Z 3}+L_{7} ; D_{o}=L_{1}+D_{4} ; L_{Z 1}=L_{2}+L_{3}+L_{4} \\
& L_{Z 2}=L_{A}+L_{C}+L_{B} ; L_{Z 3}=L_{5}+L_{6} ; A f_{33}=L_{3} / L_{Z 1} ; \\
& A f c=L_{C} / L_{Z 2} ; A f_{35}=L_{5} / L_{Z 3} ; A d_{22}=D_{2} / D_{4} ; \\
& A d_{23}=D_{3} / D_{4} ; L_{2}=\left(L_{Z 1}-L_{3}\right) / 2 ; L_{A}=\left(L_{Z 2}-L_{C}\right) / 2 \\
& L_{4}=L_{2} ; L_{B}=L_{A}
\end{aligned}
$$

\section{MODEL CHECKS}

Before performing the $S A$ optimal simulation on mufflers, 
the accuracy checks of mathematical models on three kinds of fundamental acoustical elements, including (1) a singlechamber perforated muffler; (2) a single-chamber tube-extended muffler; and (3) a side inlet/outlet single-chamber muffler, are performed using the experimental data from Sullivan et al. [21] and Chiu et al. [7] individually. As depicted in Figs. 5-7, the accuracy comparisons between theoretical and experiment data for the models are in agreement. Therefore, the proposed fundamental mathematical models with related acoustical components are acceptable. Consequently, the models linked with the numerical method are applied to the shape optimization of a three-chamber muffler hybridized with a side-inlet and a perforated tube is available.

\section{MODEL CHECKS}

In this paper, an air compressor confined within a R.C. (reinforced concrete) room is exemplified and shown in Fig. 1. The noise level in the equipment venting outlet is remarkable. To efficiently eliminate the noise, the threechamber muffler equipped with a side-inlet and a perforated tube is then considered. The spectrum of exhausted sound power level (SWL) at the muffler inlet is

\begin{tabular}{|lcccccccc|}
\hline$f(\mathrm{~Hz})$ & 63 & 125 & 250 & 500 & $1 \mathrm{k}$ & $2 \mathrm{k}$ & $4 \mathrm{k}$ & $\begin{array}{c}\text { Overall } \\
\end{array}$ \\
$S W L-d B$ & 112 & 122 & 114 & 106 & 100 & 94 & 88 & 123.1 \\
\hline
\end{tabular}

Before the minimization of a broadband noise is performed, the maximization of STL with respect to a three-chamber and perforated side mufflers at targeted pure tone $(480 \mathrm{~Hz})$ has been performed first for the purpose of an accuracy check on the SA method. As shown in Fig. 1, the available space for a muffler is $0.5 \mathrm{~m}$ in width, $0.5 \mathrm{~m}$ in height and $2.0 \mathrm{~m}$ in length. To simplify the optimization, the flow rate $\left(Q=0.2\left(\mathrm{~m}^{3} / \mathrm{s}\right)\right)$ and thickness of perforated tube $(t=0.0015(\mathrm{~m}))$ are preset in advance; the corresponding space constraints and the ranges of design parameters for each muffler are summarized in Table 1 respectively.

\section{SIMULATED ANNEALING ALGORITHM}

Simulated annealing (SA) algorithm, a local search process, simulates the softening process (annealing) of metal. The basic concept behind SA was first introduced by Metropolis et al. [11] and developed by Kirkpatrick et al. [9]. SA simulates the annealing of metal. In the physical system, annealing is the process of heating and keeping a metal at a stabilized temperature and cooling it slowly. Slow cooling allows the particles to keep their state close to the minimal energy state. In this state, the particles have a more homogeneous crystalline structure. Conversely, a fast cooling rate results in a higher distortion energy stored inside the imperfect lattice. The purpose of SA is to avoid stacking local optimal solutions during optimization.

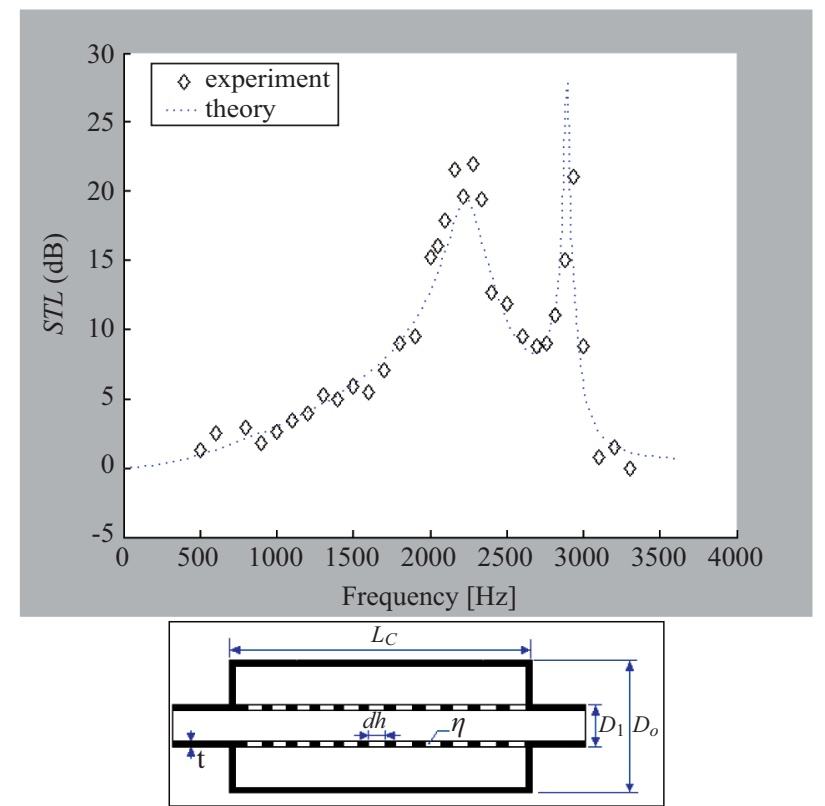

Fig. 5. Performance of single-chamber perforated muffler without the mean flow $\left[D_{1}=0.058(\mathrm{~m}), D_{o}=0.0762(\mathrm{~m}), L_{c}=0.0667(\mathrm{~m}), \mathrm{t}=\right.$ $0.0081(\mathrm{~m}), d h=0.00249(\mathrm{~m}), \eta=0.037]$ [Experiment data is from Sullivan and Crocker [21]].

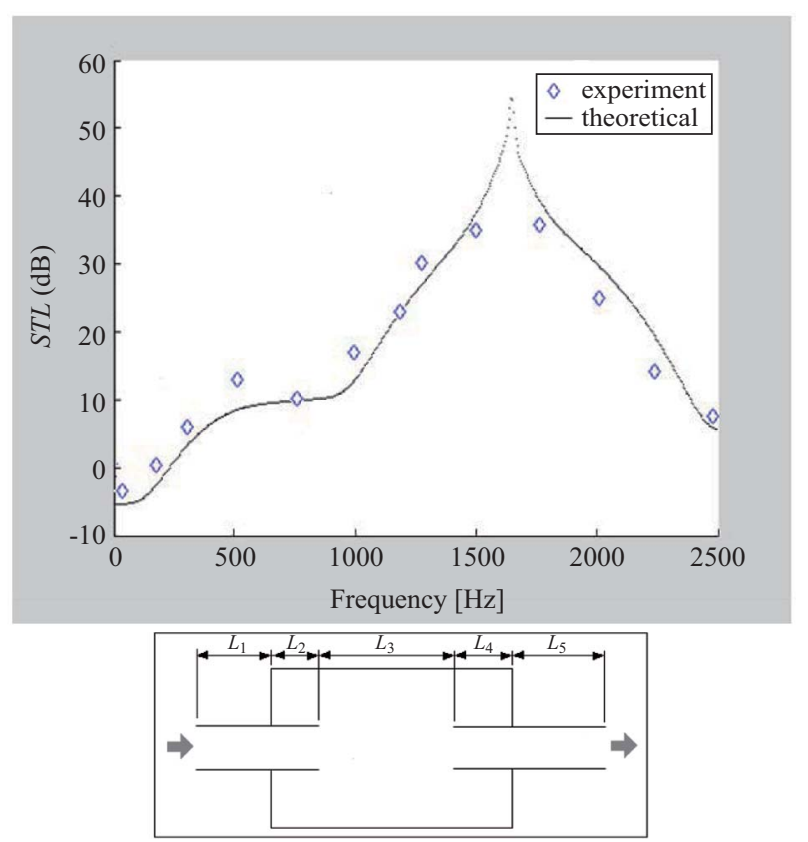

Fig. 6. Performance of a single-chamber muffler with extended tubes at the mean flow velocity of $3.4 \mathrm{~m} / \mathrm{sec}\left[D_{1}=D_{2}=0.0365(\mathrm{~m}) ; D_{o}=\right.$ $0.108(\mathrm{~m}) ; L_{1}=L_{5}=0.1(\mathrm{~m}) ; L_{2}=L_{4}=0.052(\mathrm{~m}) ; L_{3}=0.104(\mathrm{~m})$ [3]].

The algorithm starts by generating a random initial solution. The scheme of SA is a variation of the hill-climbing algorithm. All downhill movements for improvement are accepted for the decrement of the system's energy. Simultaneously, SA also allows movement resulting in solutions that are worse (uphill 


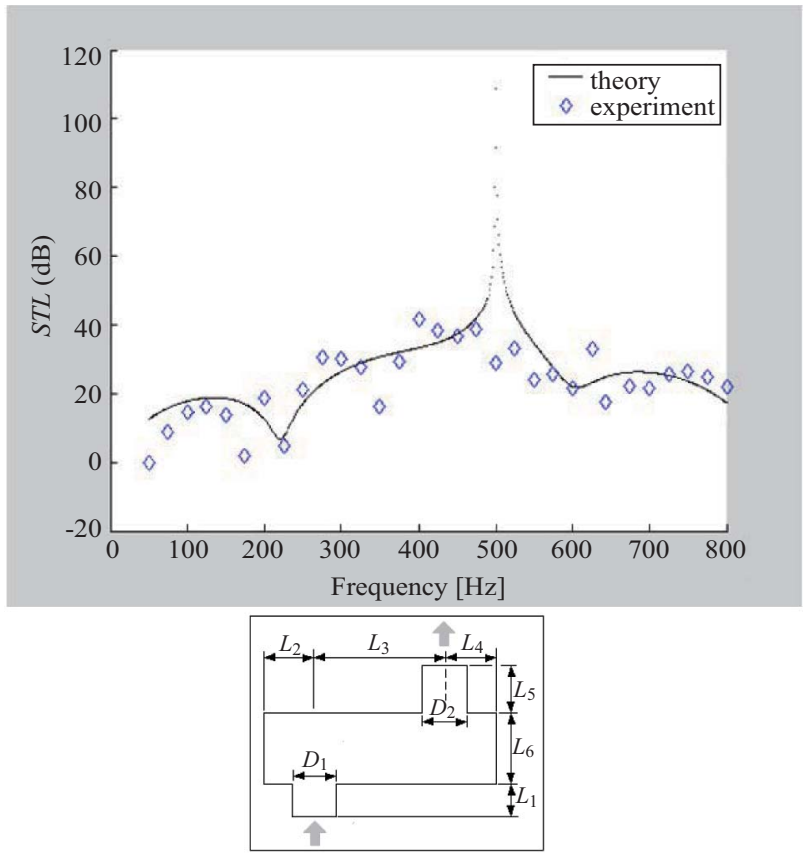

Fig. 7. Performance of single-chamber muffler with side inlet/outlet for a stationary medium $\left[L_{6}=0.2 ; L_{1}=L_{5}=0.1(\mathrm{~m}) ; D_{1}=D_{2}=0.0508\right.$ $\left.(\mathrm{m}) ; L_{2}=0.171(\mathrm{~m}) ; L_{3}=0.457(\mathrm{~m}) ; L_{4}=0.171(\mathrm{~m})\right]$ [Experiment data is from Chiu et al. [7]].

Table 1. Range of design parameters for a three-chamber muffler equipped with a side-inlet and a perforated tube.

\begin{tabular}{|c|c|}
\hline Muffler Type & Range of design parameters \\
\hline Three-chamber & Targeted $\mathrm{f}=480(\mathrm{~Hz}) ; Q=0.2\left(\mathrm{~m}^{3} / \mathrm{s}\right) ; D_{1}=0.1(\mathrm{~m})$ \\
with a side-inlet & $L_{Z 1}:[0.4,0.6] ; L_{Z 2}:[0.4,0.75] ; L_{Z 3}:[0.4,0.6]$ \\
and a perforated & $A f_{33}:[0.1,0.9] ; A f_{C}:[0.1,0.9] ; A f_{35}:[0.1,0.9] ;$ \\
tube & $D_{4}:[0.3,0.45] ; A d_{32}:[0.1,0.9] ; A d_{33}:[0.1,0.9] ;$ \\
& $\eta:[0.03,0.1] ; d h:[0.00175,0.007]$ \\
\hline
\end{tabular}

moves) than the current solution in order to escape from the local optimum.

As indicated in Fig. 8, to imitate the evolution of the $S A$ algorithm, a new random solution $\left(X^{\prime}\right)$ is chosen from the neighborhood of the current solution $(X)$. If the change in objective function (or energy) is negative (ie. $\Delta F \leq 0$ ), the new solution will be acknowledged as the new current solution with transition property $\left(p b\left(X^{\prime}\right)\right)$ of 1 .

If not (ie. $\Delta F>0)$, the new transition property $\left(p b\left(X^{\prime}\right)\right)$ varied from $0 \sim 1$ will be first calculated by the Boltzmann's factor $\left(p b\left(X^{\prime}\right)=\exp (\Delta F / C T)\right.$ as shown in (18).

$$
\begin{aligned}
p b\left(X^{\prime}\right) & =\left(\begin{array}{c}
1, \Delta F \leq 0 \\
\exp \left(\frac{-\Delta F}{C T}\right), \Delta f>0
\end{array}\right. \\
\Delta F & =F\left(X^{\prime}\right)-F(X)
\end{aligned}
$$

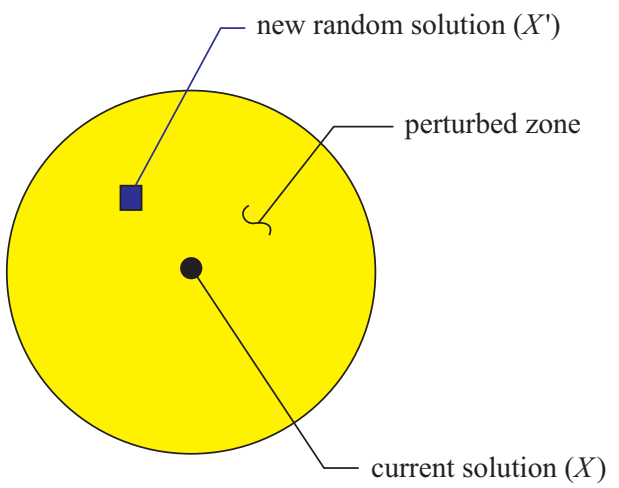

Fig. 8. New random solution in a perturbed zone.

wherein the $C$ and $T$ are the Boltzmann constant and the current temperature, correspondingly; moreover, compared with the new random probability of rand $(0,1)$. If the transition property $\left(p b\left(X^{\prime}\right)\right)$ is greater than a random number of rand $(0,1)$, the new worse solution which results in a higher energy condition will then be accepted. Otherwise, it is rejected. The algorithm repeats the perturbation of the current solution and the measurement of the change in the objective function. To reach an initial transition probability of 0.5 , the initial temperature $\left(T_{o}\right)$ is selected as 0.2 [14].

Each successful substitution of the new current solution will lead to the decay of the current temperature as

$$
T_{\text {new }}=k k * T_{\text {old }}
$$

where $k k$ is the cooling rate. The process is repeated until the predetermined number (iter) of the outer loop is reached.

The flow diagram of the SA optimization is described and shown in Fig. 9. As indicated, the SA optimization process with respect to objective functions $\left(O B J_{1}, O B J_{2}\right)$ was performed by varying control parameters- $k k$ and iter.

\section{RESULTS AND DISCUSSION}

\section{Results}

The accuracy of the SA optimization depends on the cooling rate $(k k)$ and the number of iterations (iter) [2]. To investigate the influences of the cooling rate and the number of iterations, the assessed ranges of the SA parameters of the cooling rate and the iterations are

$$
k k=(0.91,0.93,0.95,0.97,0.99) ; \text { iter }=(50 \sim 8000)
$$

The optimal results with respect to pure tone and broadband noise optimizations are described as follows:

\section{1) Pure Tone Noise Optimization}

By using (13) and (16), the maximization of STL with respect to a three-chamber and a perforated-tube muffler at 480 $\mathrm{Hz}$ was performed. As indicated in Table 2, ten sets of SA 
Table 2. Optimal design data and $S T L$ for a three-chamber side muffler hybridized with a perforated tube [optimization at targeted frequency of $480 \mathrm{~Hz}](k k=0.99)$.

\begin{tabular}{|c|c|c|c|c|c|c|c|c|c|c|c|c|c|}
\hline \multicolumn{2}{|c|}{$\begin{array}{c}S A \\
\text { parameter }\end{array}$} & \multicolumn{11}{|c|}{ Design parameters } & \multirow{2}{*}{$\begin{array}{c}\text { Performance } \\
S T L(\mathrm{~dB})\end{array}$} \\
\hline iter & $k k$ & $L_{\mathrm{Z1}}(\mathrm{m})$ & $L_{\mathrm{Z} 2}(\mathrm{~m})$ & $L_{\mathrm{Z} 3}(\mathrm{~m})$ & $A f_{33}$ & $A f_{30}$ & $A f_{35}$ & $D_{4}(\mathrm{~m})$ & $A d_{33}$ & $A d_{32}$ & $\eta$ & $d h(\mathrm{~m})$ & \\
\hline 250 & 0.91 & 0.4394 & 0.4689 & 0.4394 & 0.2574 & 0.2574 & 0.2574 & 0.3295 & 0.2574 & 0.2574 & 0.04377 & 0.002783 & 80.86 \\
\hline 250 & 0.93 & 0.4333 & 0.4583 & 0.4333 & 0.2333 & 0.2333 & 0.2333 & 0.3250 & 0.2333 & 0.2333 & 0.04166 & 0.002625 & 83.10 \\
\hline 250 & 0.95 & 0.4271 & 0.4475 & 0.4271 & 0.2086 & 0.2086 & 0.2086 & 0.3204 & 0.2086 & 0.2086 & 0.03950 & 0.002462 & 87.08 \\
\hline 250 & 0.97 & 0.4011 & 0.4020 & 0.4011 & 0.1045 & 0.1045 & 0.1045 & 0.3008 & 0.1045 & 0.1045 & 0.03039 & 0.001780 & 113.2 \\
\hline 250 & $\underline{0.99}$ & 0.4082 & 0.4143 & 0.4082 & 0.1327 & 0.1327 & 0.1327 & 0.3061 & 0.1327 & 0.1327 & 0.03286 & 0.001964 & 138.0 \\
\hline 500 & 0.99 & 0.4074 & 0.4129 & 0.4074 & 0.1294 & 0.1294 & 0.1294 & 0.3055 & 0.1294 & 0.1294 & 0.03258 & 0.001943 & 139.7 \\
\hline 1000 & 0.99 & 0.4079 & 0.4138 & 0.4079 & 0.1314 & 0.1314 & 0.1314 & 0.3059 & 0.1314 & 0.1314 & 0.03275 & 0.001956 & 149.1 \\
\hline 2000 & 0.99 & 0.4078 & 0.4136 & 0.4078 & 0.1311 & 0.1311 & 0.1311 & 0.3058 & 0.1311 & 0.1311 & 0.03272 & 0.001954 & 166.8 \\
\hline 4000 & 0.99 & 0.4077 & 0.4135 & 0.4077 & 0.1309 & 0.1309 & 0.1309 & 0.3058 & 0.1309 & 0.1309 & 0.03270 & 0.001953 & 166.3 \\
\hline 8000 & $\underline{0.99}$ & 0.4077 & 0.4135 & 0.4077 & 0.1309 & 0.1309 & 0.1309 & $\underline{0.3058}$ & 0.1309 & 0.1309 & $\underline{0.03270}$ & $\underline{0.001953}$ & 167.3 \\
\hline
\end{tabular}

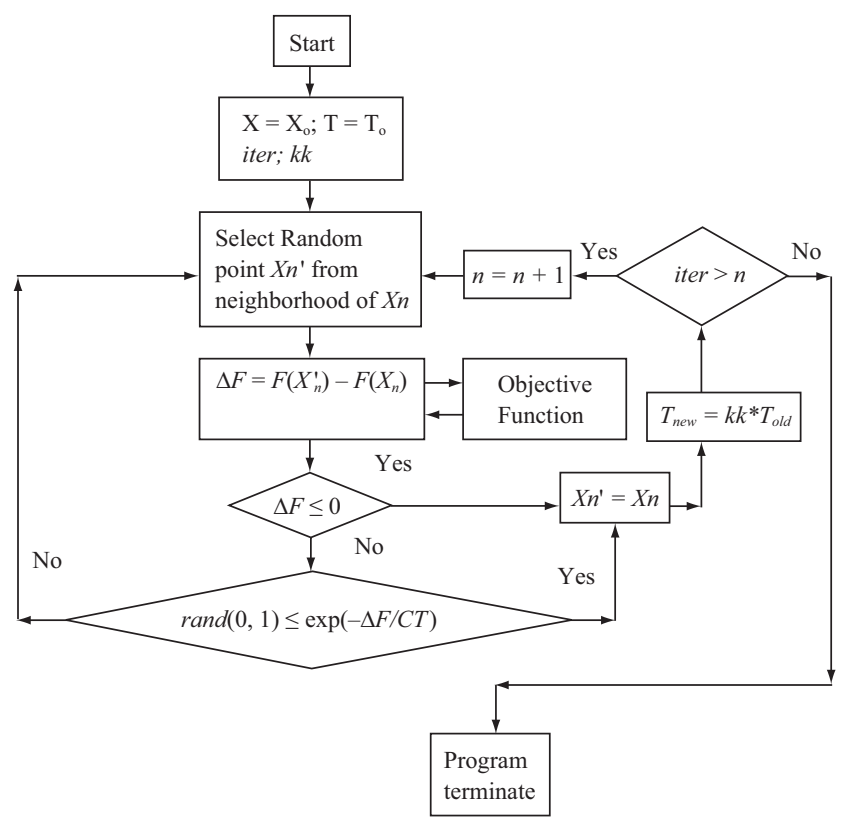

Fig. 9. Flow diagram of SA optimization.

parameters are tried. Obviously, the optimal design data can be obtained from the last set of SA parameters at $(k k$, iter $)=$ $(0.99,8000)$. In addition, the related $S T L$ with respect to different parameters are plotted and illustrated in Figs. 10, 11. As indicated in Fig. 10, the better result is achieved at $k k=0.99$; In addition, Fig. 11 reveals that the higher iter will increase the accuracy of $O B J$ value. Using the optimal design in theoretical calculation, the resultant curve of $S T L$ with respect to frequencies is plotted and depicted in Fig. 12. As revealed in Fig. 12, the $S T L$ is precisely maximized at the desired frequencies of $480 \mathrm{~Hz}$.

\section{2) Broadband Noise Optimization}

By using (15) and (17) and with $(k k=0.99)$ in the SA parameter, the optimal muffler design parameters and sizes in

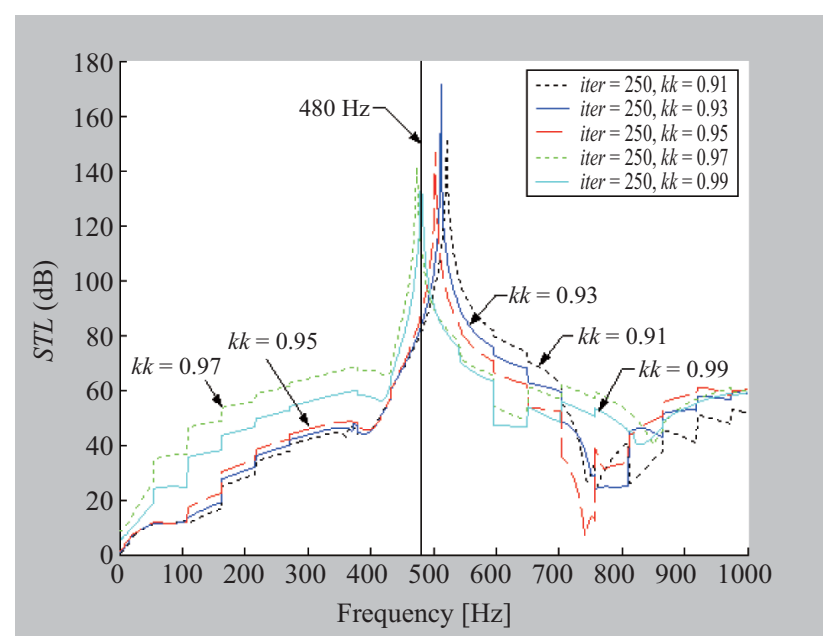

Fig. 10. $S T L$ with respect to frequency at different cooling rates [optimized at targeted frequency of $480 \mathrm{~Hz}$ and iter of 250 for a three-chamber side muffler hybridized with a perforated tube].

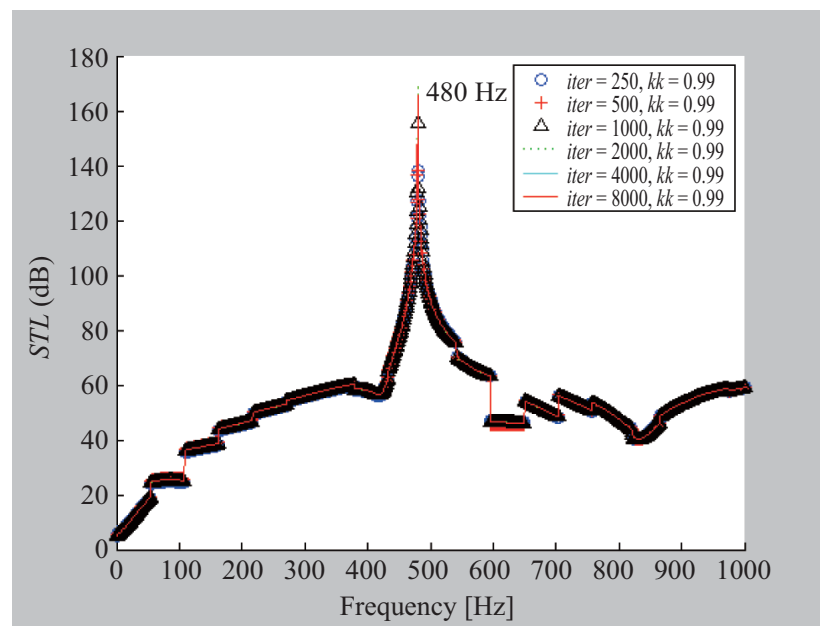

Fig. 11. $S T L$ with respect to frequency at different iteration numbers [optimized at targeted frequency of $480 \mathrm{~Hz}$ and $k \boldsymbol{k}$ of 0.99 for a three-chamber side muffler hybridized with a perforated tube]. 
Table 3. Optimal design data and overall $S W L$ for a three-chamber muffler hybridized with a perforated tube [optimization at broadband frequency] $(k k=0.99)$.

\begin{tabular}{|c|c|c|c|c|c|c|c|c|c|c|c|c|}
\hline $\begin{array}{c}\text { SA } \\
\text { parameter }\end{array}$ & \multicolumn{10}{|c|}{ Design parameters } & Performance \\
\hline iter & $L_{\mathrm{Z1}}(\mathrm{m})$ & $L_{\mathrm{Z2}}(\mathrm{m})$ & $L_{\mathrm{Z} 3}(\mathrm{~m})$ & $A f_{33}$ & $A f_{30}$ & $A f_{35}$ & $D_{4}(\mathrm{~m})$ & $A d_{33}$ & $A d_{32}$ & $\eta$ & $d h(\mathrm{~m})$ & $S W L(\mathrm{~dB})$ \\
\hline 50 & 0.4084 & 0.4147 & 0.4084 & 0.1336 & 0.1336 & 0.1336 & 0.3063 & 0.1336 & 0.1336 & 0.1336 & 0.02219 & 90.01 \\
\hline 100 & 0.4063 & 0.4109 & 0.4063 & 0.1250 & 0.1250 & 0.1250 & 0.3047 & 0.1250 & 0.1250 & 0.1250 & 0.01906 & 87.02 \\
\hline 250 & 0.4006 & 0.4011 & 0.4006 & 0.1025 & 0.1025 & 0.1025 & 0.3005 & 0.1025 & 0.1025 & 0.1025 & 0.0190 & 77.99 \\
\hline 500 & 0.4006 & 0.4011 & 0.4006 & 0.1025 & 0.1025 & 0.1025 & 0.3005 & 0.1025 & 0.1025 & 0.1025 & 0.0190 & 77.99 \\
\hline 1000 & 0.4002 & 0.4004 & 0.4002 & 0.1008 & 0.1025 & 0.1008 & 0.3002 & 0.1008 & 0.1008 & 0.1008 & 0.0130 & 77.26 \\
\hline 2000 & 0.4000 & 0.4001 & 0.4000 & 0.1001 & 0.1001 & 0.1001 & 0.3000 & 0.1001 & 0.1001 & 0.1001 & 0.0105 & 76.96 \\
\hline$\underline{\mathbf{4 0 0 0}}$ & $\underline{\mathbf{0 . 4 0 0 0}}$ & $\underline{\mathbf{0 . 4 0 0 0}}$ & $\underline{\mathbf{0 . 4 0 0 0}}$ & $\underline{\mathbf{0 . 1 0 0 1}}$ & $\underline{\mathbf{0 . 1 0 0 1}}$ & $\underline{\mathbf{0 . 1 0 0 1}}$ & $\underline{\mathbf{0 . 3 0 0 0}}$ & $\underline{\mathbf{0 . 1 0 0 1}}$ & $\underline{\mathbf{0 . 1 0 0 1}}$ & $\underline{\mathbf{0 . 1 0 0 1}}$ & $\underline{\mathbf{0 . 0 1 0 2}}$ & 76.92 \\
\hline
\end{tabular}

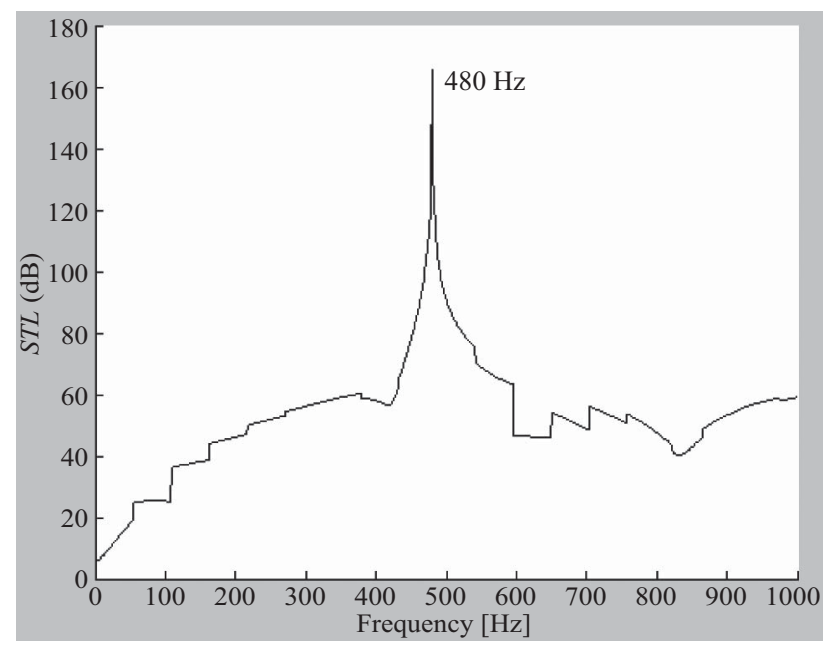

Fig. 12. STL with respect to frequency [using optimal design data for a three-chamber side muffler hybridized with a perforated tube].

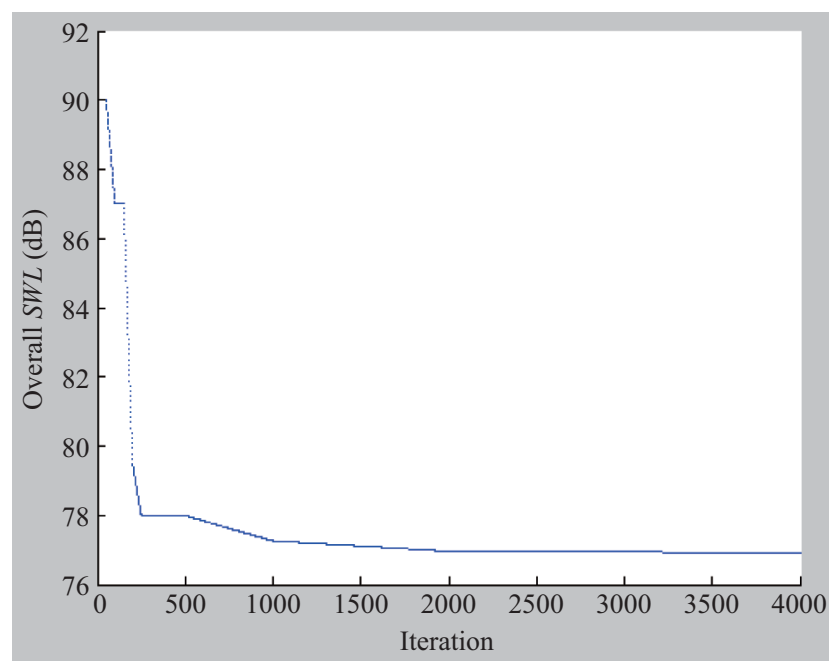

Fig. 13. History curve of $S W L$ with respect to iteration $[k k=0.99$ for a three-chamber side muffler hybridized with a perforated tube].

minimizing the sound power level at the muffler's outlet is achieved and summarized in Table 3 . The related history

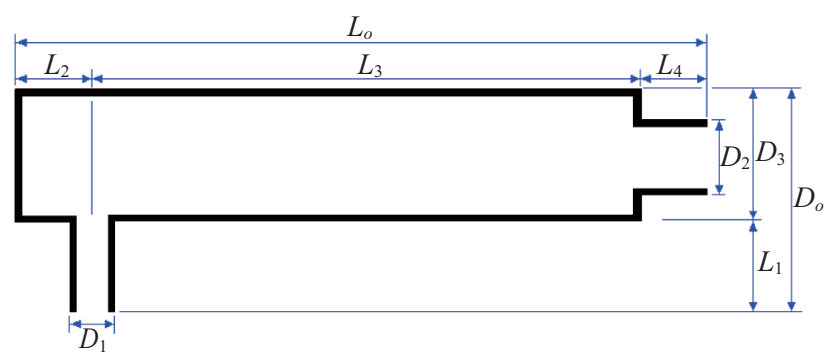

Fig. 14. The outline of a one-chamber side muffler.

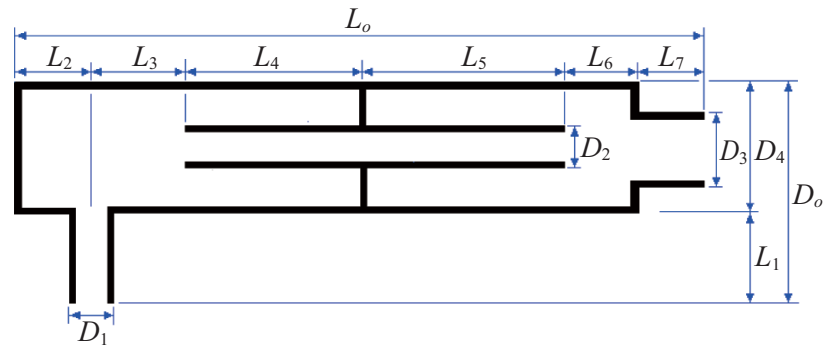

Fig. 15. The outline of a two-chamber side muffler hybridized with a non-perforated tube.

curves of fitness with respect to generations are plotted in Fig. 13.

To appreciate the acoustical effect in the chambers and the perforated/non-perforated tube, a one-chamber side muffler shown in Fig. 14 and a two-chamber side muffler hybridized with a non-perforated tube shown in Fig. 15 are investigated under the same space-constrained condition. The resultant STL profiles of three kinds of mufflers - a one-chamber side muffler, a two-chamber side muffler hybridized with a nonperforated tube, and a three-chamber side muffler hybridized with a perforated tube are plotted together and compared with the $S W L O$ - an un-silenced SWL - in Fig. 16.

\section{Discussion}

To achieve a better and sufficient optimization, the selection of appropriate $S A$ parameters set is essential. As illus- 


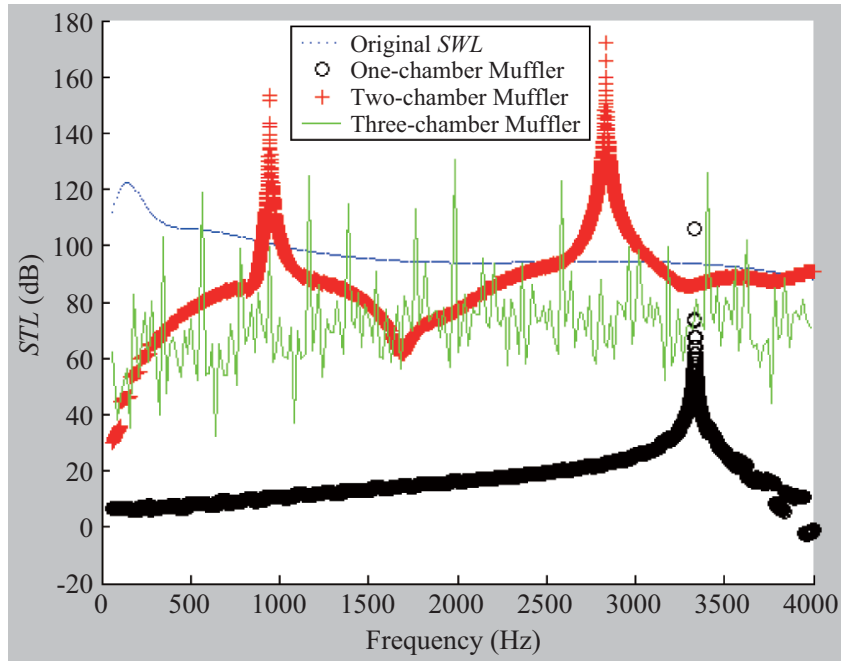

Fig. 16. Comparison of $S T L$ spectrum with respect to three kinds of mufflers.

Table 4. Resultant $S W L$ for three kinds of mufflers.

\begin{tabular}{|c|c|}
\hline Muffler Type & $\begin{array}{c}\text { Resultant } S W L \text { after adding a } \\
\text { muffler }(\mathrm{dB})\end{array}$ \\
\hline One-chamber with side inlet & 116.4 \\
\hline $\begin{array}{c}\text { Double-chamber with side Inlet and } \\
\text { internal extended tube }\end{array}$ & 83.02 \\
\hline $\begin{array}{c}\text { Three-chamber with side inlet and } \\
\text { internal perforated tube }\end{array}$ & 76.92 \\
\hline
\end{tabular}

trated in Table 3, the optimal design data has been achieved at ( $k k$, iter) of $(0.99,4000)$. According to the related history curves in Figs. 10 12, the fitness reaches the maximum at iter of 4000 in which the variation of Fitness with respect to iteration is trivial. Therefore, the optimal result in Table 3 can be accepted. To appreciate the acoustical effect in the chambers and the perforated/non-perforated tube, a one-chamber side muffler and a two-chamber side muffler hybridized with a non-perforated tube are investigated under the same spaceconstrained condition. To sum up the final results in Table 4, it can be found that the sound power levels of three mufflers can be reduced from $123.1 \mathrm{~dB}(\mathrm{~A})$ to $116.4,83.0$ and $76.9 \mathrm{~dB}$ respectively. As investigated in Fig. 16, the three-chamber muffler hybridized with a perforated tube owns the best STL; on the country, the one-chamber muffler without tube inside has the lowest $S T L$. As indicated in Table 4, the overall noise reduction in one-chamber muffler is $6.7 \mathrm{~dB}$ only. The overall noise reduction in a two-chamber muffler is $40.1 \mathrm{~dB}$. For the three-chamber muffler hybridized with a perforated tube, the overall noise reduction reaches $46 \mathrm{~dB}$. Consequently, the chamber and internal tube play essential roles in eliminating noise level. Moreover, the mechanism of a perforated tube in conjunction with the resonated chamber has the best noise reduction than that of non-perforated tube.

\section{CONCLUSION}

It has been shown that two kinds of SA parameters $-k k$, iter - play essential roles in the solution's accuracy during the SA optimization. Besides, the higher iteration will increase the accuracy. Before broadband noise optimization is performed, the pure-tone optimization of a three-chamber has been carried out. Results reveal that the maximal STL is precisely located at the desired tone which means that the precision of SA technique in adjusting eleven design parameter of muffler is confidential.

As investigated in Section 7, a three-chamber side muffler hybridized with a perforated tube exhibits an excellent acoustical ability beyond the other mufflers - a one-chamber side muffler and a two-chamber side muffler hybridized with a non-perforated tube. Beyond a doubt, the acoustical mechanism of a perforated tube installed inside a multi-chamber side-inlet muffler has the better noise reduction than that of the non-perforated tube in mufflers.

\section{ACKNOWLEDGMENTS}

The author acknowledges the financial support of the National Science Council (NSC 95-2218-E-235-002), ROC.

\section{NOMENCLATURE}

This paper is constructed on the basis of the following notations:

$C_{o}: \quad$ sound speed $\left(\mathrm{m} \mathrm{s}^{-1}\right)$

$d h$ : diameter of perforated holes on a perforated tube (m)

$D_{\mathrm{i}}: \quad$ diameter of the ith tube $(\mathrm{m})$

$D_{\mathrm{o}}: \quad$ maximum diameter of the muffler $(\mathrm{m})$

$f: \quad$ cyclic frequency $(\mathrm{Hz})$

iter: maximum iteration in SA optimization

$j: \quad$ imaginary unit

$k k$ : cooling rate in $\mathrm{SA}$

$k: \quad$ wave number $\left(=\omega / C_{o}\right)$

$L_{i}$ : $\quad$ lengths of ith ducts $(\mathrm{m})$

$L_{A}, L_{B}$ : length of the non-perforated segments in the perforated tube $(\mathrm{m})$

$L_{C}$ : length of the perforated segment in the perforated tube (m)

$L_{o}: \quad$ total length of the muffler (m)

$L_{Z-i}: \quad$ length of the ith chamber (m)

$M_{i}$ : $\quad$ mean flow Mach number at $i t h$ node

$O B J_{i}: \quad$ objective function

$p b(T): \quad$ transition probability

$p_{i}: \quad$ acoustic pressure at $i t h$ node $(\mathrm{Pa})$

$Q: \quad$ volume flow rate of venting gas $\left(\mathrm{m}^{3} \mathrm{~s}^{-1}\right)$

$S_{i}$ : $\quad$ section area at ith node $\left(\mathrm{m}^{2}\right)$

STL: $\quad$ sound transmission loss $(\mathrm{dB})$

$S W L_{i}: \quad$ the silenced SWL at silencer outlet at ith octave band frequency 
$S W L_{T}: \quad$ the overall silenced SWL at silencer outlet

$S W L O_{i}$ : the unsilenced SWL at silencer inlet at ith octave band frequency

$T_{i j}$ : $\quad$ components of a four-pole transfer system matrix

$T C_{i j}: \quad$ components of four-pole transfer matrices for a contracted duct

$T E_{i j}$ : components of four-pole transfer matrices for a side inlet duct

$T P_{\mathrm{ij}}$ : $\quad$ components of a four-pole transfer matrix for a perforated duct

$T S_{i j}$ : $\quad$ components of four-pole transfer matrices for a straight duct

$T S E C_{i j}$ : components of four-pole transfer matrices for an extended duct at the contracted part

$T S E E_{i j}$ : components of four-pole transfer matrices for an extended duct at the expanded part

$u$ : $\quad$ acoustical particle velocity in a perforated hole

$u_{i}$ : $\quad$ acoustic particle velocity at $i t h$ node $\left(\mathrm{m} \mathrm{s}^{-1}\right)$

$\rho_{o}: \quad$ air density of steady flow $\left(\mathrm{kg} \mathrm{m}^{-3}\right)$

$\rho_{i}$ : $\quad$ fluctuated density at ith node $\left(\mathrm{kg} \mathrm{m}^{-3}\right)$

$\varsigma$ : $\quad$ specific acoustical impedance of a perforated tube

$\eta: \quad$ the porosity of a perforated tube

$\varepsilon_{i}: \quad$ ith eigen value of $[\mathrm{N}]$

$[\Omega]_{4 x 4}$ : the model matrix formed by an eigen vector $\Omega_{4 x 1}$ of $[\mathrm{N}]_{4 \times 4}$

\section{APPENDIX A}

\section{Transfer Matrix of a Perforated Duct}

As indicated in Fig. 17, the perforated resonator is composed of an inner perforated tube and an outer resonating chamber. Based on Sullivan and Crocker's derivation [9], the continuity equations and momentum equations with respect to inner and outer tubes at nodes 8 and $8 \mathrm{a}$ in a concentric resonator are

\section{Inner tube:}

continuity equation

$$
V \frac{\partial \rho_{8}}{\partial x}+\rho_{o} \frac{\partial u_{8}}{\partial x}+\frac{4 \rho_{o}}{D_{1}} u+\frac{\partial \rho_{8 a}}{\partial t}=0
$$

momentum equation:

$$
\rho_{o}\left(\frac{\partial}{\partial t}+V \frac{\partial}{\partial x}\right) u_{8}+\frac{\partial p_{8}}{\partial x}=0
$$

Outer tube:

continuity equation

$$
\rho_{o} \frac{\partial u_{8 a}}{\partial x}-\frac{4 D_{2} \rho_{o}}{D_{o}^{2}-D_{1}^{2}} u+\frac{\partial \rho_{8 a}}{\partial t}=0
$$

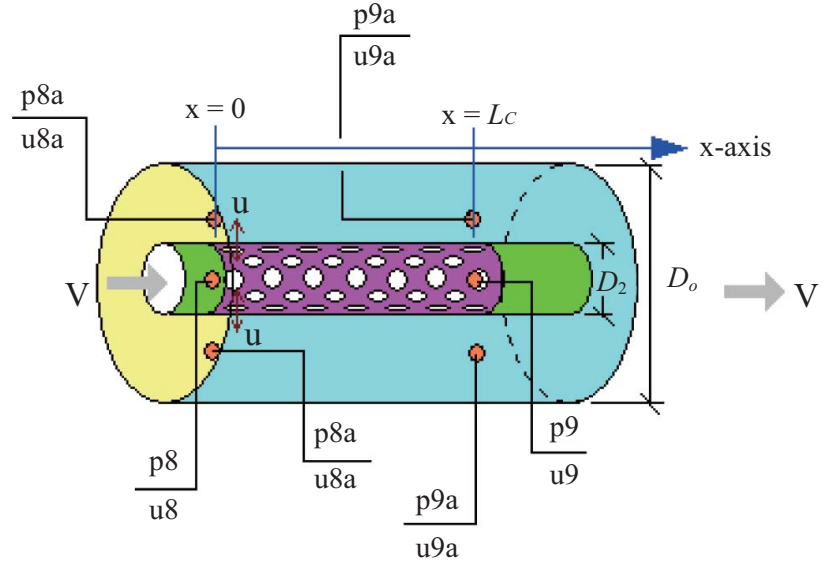

Fig. 17. Acoustic field of a one-chamber with a perforated tube.

$$
\rho_{o} \frac{\partial u_{8 a}}{\partial t}+\frac{\partial p_{8 a}}{\partial x}=0
$$

Assuming that the acoustic wave is a harmonic motion

$$
p(x, t)=P(x) \cdot e^{j \omega t}
$$

under the isentropic processes in ducts, it has

$$
P(x)=\rho(x) \cdot c_{o}^{2}
$$

Assuming that the perforation along the inner tube is uniform (ie. $d \varsigma / d x=0$ ). The acoustic impedance of the perforation $\left(\rho_{o} c_{o} \varsigma\right)$ is

$$
\rho_{o} c_{o} \varsigma=\frac{p_{8}(x)-p_{8 a}(x)}{u(x)}
$$

where $\varsigma$ is the specific acoustical impedance of the perforated tube. According to the experience formula of $\varsigma,[9,23]$, the empirical formulations for the perforates with or without a mean flow are adopted in this study.

By substituting (A5)-(A7) into (A1)-(A4), eliminating $u_{8}$ and $u_{8 a}$, and doing rearranging, we have

$$
\left[\begin{array}{cc}
D^{2}+\alpha_{1} D+\alpha_{2} & \alpha_{3} D+\alpha_{4} \\
\alpha_{5} D+\alpha_{6} & D^{2}+\alpha_{7} D+\alpha_{8}
\end{array}\right]\left[\begin{array}{c}
p_{8} \\
p_{8 a}
\end{array}\right]=\left[\begin{array}{l}
0 \\
0
\end{array}\right]
$$

Developing (A8) yields

$$
\begin{gathered}
p_{8}^{\prime \prime}+\alpha_{1} p_{8}^{\prime}+\alpha_{2} p_{8}+\alpha_{3} p_{8 a}^{\prime}+\alpha_{4} p_{8 a}=0 \\
\alpha_{5} p_{8}^{\prime}+\alpha_{6} p_{8}+p_{8 a}^{\prime \prime}+\alpha_{7} p_{8 a}^{\prime}+\alpha_{8} p_{8 a}=0
\end{gathered}
$$


Let $p_{8}^{\prime}=\frac{d p_{8}}{d x}=y_{1}, p_{8 a}^{\prime}=\frac{d p_{8 a}}{d x}=y_{2}, p_{8}=y_{3}, p_{8 a}=y_{4}$

According to (A9) and (A10), the new matrix between $\left\{y^{\prime}\right\}$ and $\{y\}$ is

$$
\left[\begin{array}{l}
y_{1}^{\prime} \\
y_{2}^{\prime} \\
y_{3}^{\prime} \\
y_{4}^{\prime}
\end{array}\right]=\left[\begin{array}{cccc}
-\alpha_{1} & -\alpha_{3} & -\alpha_{2} & -\alpha_{4} \\
-\alpha_{5} & -\alpha_{7} & -\alpha_{6} & -\alpha_{8} \\
1 & 0 & 0 & 0 \\
0 & 1 & 0 & 0
\end{array}\right]\left[\begin{array}{l}
y_{1} \\
y_{2} \\
y_{3} \\
y_{4}
\end{array}\right]
$$

which can be briefly expressed as

$$
\begin{gathered}
\left\{y^{\prime}\right\}=[\mathrm{N}]\{y\} \\
\text { Let }\{y\}=[\Omega]\{\Gamma\}
\end{gathered}
$$

which is

$$
\left[\begin{array}{c}
d p_{8} / d x \\
d p_{8 a} / d x \\
p_{8} \\
p_{8 a}
\end{array}\right]=\left[\begin{array}{llll}
\Omega_{1,1} & \Omega_{1,2} & \Omega_{1,3} & \Omega_{1,4} \\
\Omega_{2,1} & \Omega_{2,2} & \Omega_{2,3} & \Omega_{2,4} \\
\Omega_{3,1} & \Omega_{3,2} & \Omega_{3,3} & \Omega_{3,4} \\
\Omega_{4,1} & \Omega_{4,2} & \Omega_{4,3} & \Omega_{4,4}
\end{array}\right]\left[\begin{array}{c}
\Gamma_{1} \\
\Gamma_{2} \\
\Gamma_{3} \\
\Gamma_{4}
\end{array}\right]
$$

$[\Omega]_{4 \times 4}$ is the model matrix formed by four sets of eigen vectors $\Omega_{4 \times 1}$ of $[\mathrm{N}]_{4 \times 4}$.

Substituting (A12) into (A11) and then multiplying $[\Omega]^{-1}$ on both sides,

$$
\begin{gathered}
{[\Omega]^{-1}[\Omega]\left\{\Gamma^{\prime}\right\}=[\Omega]^{-1}[\mathrm{~N}][\Omega]\{\Gamma\}} \\
\operatorname{Set}[\chi]=[\Omega]^{-1}[\mathrm{~N}][\Omega]=\left[\begin{array}{cccc}
\varepsilon_{1} & 0 & 0 & 0 \\
0 & \varepsilon_{2} & 0 & 0 \\
0 & 0 & \varepsilon_{3} & 0 \\
0 & 0 & 0 & \varepsilon_{4}
\end{array}\right]
\end{gathered}
$$

where $\varepsilon_{i}$ is the eigen value of [N].

Equation (A12) can be thus rewritten as

$$
\left\{\Gamma^{\prime}\right\}=[\chi]\{\Gamma\}
$$

Equation (A12) is a decoupled equation. The related solution can then be obtained

$$
\Gamma_{i}=k_{i} e^{\varepsilon_{i} x}
$$

Using (A2), (A4), (A12a), and (A16), the relationship of acoustic pressure and particle velocity can be obtained

$$
\left[\begin{array}{c}
p_{8}(x) \\
p_{8 a}(x) \\
\rho_{o} c_{o} u_{8}(x) \\
\rho_{o} c_{o} u_{8 a}(x)
\end{array}\right]=\left[\begin{array}{llll}
\mathrm{H}_{1,1} & \mathrm{H}_{1,2} & \mathrm{H}_{1,3} & \mathrm{H}_{1,4} \\
\mathrm{H}_{2,1} & \mathrm{H}_{2,2} & \mathrm{H}_{2,3} & \mathrm{H}_{2,4} \\
\mathrm{H}_{3,1} & \mathrm{H}_{3,2} & \mathrm{H}_{3,3} & \mathrm{H}_{3,4} \\
\mathrm{H}_{4,1} & \mathrm{H}_{4,2} & \mathrm{H}_{4,3} & \mathrm{H}_{4,4}
\end{array}\right]\left[\begin{array}{c}
k_{1} \\
k_{2} \\
k_{3} \\
k_{4}
\end{array}\right]
$$

Substituting $\mathrm{x}=0$ and $\mathrm{x}=L_{C}$ into (A17) and doing rearranging yield

$$
\left[\begin{array}{c}
p_{8}(0) \\
p_{8 a}(0) \\
\rho_{o} c_{o} u_{8}(0) \\
\rho_{o} c_{o} u_{8 a}(0)
\end{array}\right]=[\mathrm{A}]\left[\begin{array}{c}
p_{8}\left(L_{C}\right) \\
p_{8 a}\left(L_{C}\right) \\
\rho_{o} c_{o} u_{8}\left(L_{C}\right) \\
\rho_{o} c_{o} u_{8 a}\left(L_{C}\right)
\end{array}\right]
$$

where

$$
[\mathrm{A}]=[\mathrm{H}(0)]\left[\mathrm{H}\left(L_{C}\right)\right]^{-1}
$$

To obtain the transform matrix between inlet $(x=0)$ and outlet $\left(x=L_{C}\right)$ of inner tubes, two boundary conditions for the outer tube at $x=0$ and $x=L_{C}$ are taken into calculation and listed below.

$$
\begin{aligned}
& \frac{p_{8 a}(0)}{-u_{8 a}(0)}=-j \rho_{o} c_{o} \cot \left(k L_{A}\right) \\
& \frac{p_{8 a}\left(L_{C}\right)}{u_{8 a}\left(L_{C}\right)}=-j \rho_{o} c_{o} \cot \left(k L_{B}\right)
\end{aligned}
$$

By substituting (A19a) and (A19b) into (A18) and developing them, the transfer matrix is deduced

$$
\left[\begin{array}{c}
p_{8}(0) \\
\rho_{o} c_{o} u_{8}(0)
\end{array}\right]=\left[\begin{array}{cc}
T P_{1,1} & T P_{1,2} \\
T P_{2,1} & T P_{2,2}
\end{array}\right]\left[\begin{array}{c}
p_{8}\left(L_{C}\right) \\
\rho_{o} c_{o} u_{8}\left(L_{C}\right)
\end{array}\right]
$$

or in a brief form of

$$
\left[\begin{array}{c}
p_{8} \\
\rho_{o} c_{o} u_{8}
\end{array}\right]=\left[\begin{array}{cc}
T P_{1,1} & T P_{1,2} \\
T P_{2,1} & T P_{2,2}
\end{array}\right]\left[\begin{array}{c}
p_{9} \\
\rho_{o} c_{o} u_{9}
\end{array}\right]
$$

\section{REFERENCES}

1. Alley, B. C., Dufresne, R. M., Kanji, N., and Reesal, M. R., "Costs of workers' compensation claims for hearing loss," Journal of Occupational Medicine, Vol. 31, pp. 134-138 (1989).

2. Cave, A., Nahavandi, S., and Kouzani, A., "Simulation optimization for process scheduling through simulated annealing," Proceedings of the 2002 Winter Simulation Conference, pp. 1909-1913 (2002).

3. Chang, Y. C., Yeh, L. J., and Chiu, M. C., "GA optimization on singlechamber muffler hybridized with extended tube under space constraints," Archives of Acoustics, Vol. 29, No. 4, pp. 577-596 (2004). 
4. Chang, Y. C., Yeh, L. J., and Chiu, M. C., "Numerical studies on constrained venting system with side inlet/outlet mufflers by GA optimization," Acta Acustica, Vol. 90, No. 1-1, pp. 1-114 (2004).

5. Chiu, M. C., "Shape optimization of double-chamber side mufflers with extended tube by using four-pole matrix and simulated annealing method," Journal of Mechanics, Vol. 24, pp. 31-43 (2008).

6. Chiu, M. C. and Chang, Y. C., "Numerical studies on venting system with multi-chamber perforated mufflers by GA optimization," Applied Acoustics, Vol. 69, No. 11, pp. 1017-1037, 2008.

7. Chiu, M. C., Yeh, L. J., Chang, Y. C., Lai, G. J., Her, M. G., and Lan, T. S., "Shape optimization of single-chamber mufflers with side inlet/outle by using boundary element method, mathematic gradient method and genetic algorithm," Proceedings of the $23^{\text {th }}$ National Conference on the Chinese Society of Mechanical Engineers, CII (C7-006), pp. 1-6 (2006).

8. Kaiser, L. and Bernhardt, H., "Noise control on computer and business equipment using speed control blowers," IEEE, Vol. 2, pp. 114-117 (1989).

9. Kirkpatrick, S., Gelatt, C. D., Jr. and Vecchi, M. P., "Optimization by simulated annealing," Science, Vol. 220, No. 4598, pp. 671-680 (1983).

10. Magrab, E. B., Environmental Noise Control, John Wiley \& Sons, New York (1975).

11. Metropolis, A., Rosenbluth, W., Rosenbluth, M. N., Teller, H., and Teller, E., "Equation of static calculations by fast computing machines," The Journal of Chemical Physics, Vol. 21, No. 6, pp. 1087-1092 (1953).

12. Munjal, M. L., Acoustics of Ducts and Mufflers with Application to Exhaust and Ventilation System Design, John Wiley \& Sons, New York (1987).

13. Munjal, M. L., "Plane wave analysis of side inlet/outlet chamber mufflers with mean flow," Applied Acoustics, Vol. 52, pp. 165-175 (1997).

14. Nolle, L., Armstrong, D. A., Hopgood, A. A., and Ware, J. A., "Simulated annealing and genetic algorithms applied to finishing mill optimization for hot rolling of wide steel strip," International of Knowledge-Based Intelligent Engineering System, Vol. 6, No. 2, pp. 104-111 (2002).

15. Peat, K. S., "A numerical decoupling analysis of perforated pipe silencer elements," Journal of Sound and Vibration, Vol. 123, No. 2, pp. 199-212 (1988).

16. Rao, K. N. and Munjal, M. L., "A generalized decoupling method for analyzing perforated element mufflers," Proceedings of the 1984 Nelson Acoustics Conference, Madison, WI (1984).

17. Rao, K. N. and Munjal, M. L., "Experimental evaluation of iimpedance of perforates with grazing flow," Journal of Sound and Vibration, Vol. 123, pp. 283-295 (1986).

18. Sathyanarayana, Y. and Munjal, M. L., "A hybrid approach for aeroacoustic analysis of the engine exhaust system," Applied Acoustics, Vol. 60, pp. 425-450 (2000).

19. Sullivan, J. W., "A method for modeling perforated tube muffler components I: Theory," The Journal of the Acoustical Society of America, Vol. 66, pp. 772-778 (1979).

20. Sullivan, J. W., "A method of modeling perforated tube muffler components II: Theory," The Journal of the Acoustical Society of America, Vol. 66, pp. 779-788 (1979).

21. Sullivan, J. W. and Crocker, M. J., "Analysis of concentric tube resonators having unpartitioned cavities," The Journal of the Acoustical Society of America, Vol. 64, pp. 207-215 (1978).

22. Thawani, P. T. and Jayaraman, K., "Modeling and applications of straightthrough resonators," The Journal of the Acoustical Society of America, Vol. 73, No. 4, pp. 1387-1389 (1983).

23. Yeh, L. J., Chang, Y. C., Chiu, M. C., and Lai, G. J., "Computer-aided optimal design of a single-chamber muffler with side inlet/outlet under space constraints," Journal of Marine Science and Technology, Vol. 11, No. 4, pp. 1-8 (2003). 